\title{
Neurocognitive Inhibitory Control Ability Performance and Correlations with Biochemical Markers in Obese Women
}

\author{
Huei-Jhen Wen ${ }^{1,2, *(D)}$ and Chia-Liang Tsai ${ }^{3, *(D)}$ \\ 1 Center of Physical Education, College of Education and Communication, Tzu Chi University, \\ Hualien 970301, Taiwan \\ 2 Sports Medicine Center, Tzu Chi Hospital, Hualien 970410, Taiwan \\ 3 Institution of Physical Education, Health and Leisure Studies, National Cheng Kung University, \\ Tainan 701401, Taiwan \\ * Correspondence: win@mail.tcu.edu.tw (H.-J.W.); andytsai@mail.ncku.edu.tw (C.-L.T.); \\ Tel.: +886-3-8565301 (ext. 1217) (H.-J.W.); +886-6-2757575 (ext. 81809) (C.-L.T.)
}

Received: 19 February 2020; Accepted: 13 April 2020; Published: 15 April 2020

\begin{abstract}
Inhibitory control, the ability to suppress prepotent responses and resist irrelevant stimuli, is thought to play a critical role in the maintenance of obesity. However, electrophysiological performance related to different inhibitory control processes and their relationship with motor response inhibition and cognitive interference and potential biochemical mechanisms in middle-aged, obese women are as yet unclear. This work thus compared different neurocognitive Go/Nogo and Stroop task performance in healthy sedentary normal-weight and obese women, as well as their correlation with biochemical markers. Twenty-six healthy, sedentary obese women (obese group) and 26 age-matched (21-45 years old) normal-weight women (control group) were the participants, categorized by body mass index and percentage fat, as measured with dual-energy X-ray absorptiometry. They provided a fasting blood sample and performed two cognitive tasks (i.e., Go/Nogo and Stroop tasks) with concomitant electrophysiological recording. The N2 and P3 waveforms of event-related potential (ERP) were recorded. Although the between-group behavioral performance was comparable, the obese group relative to the control group showed significantly longer N2 latency and smaller P3 amplitude in the Stroop task and smaller N2 and P3 amplitudes in the Go/Nogo task. Significant inflammation response indices (e.g., CRP, leptin, adiponectin/leptin ratio) were observed in the obese group. The Nogo P3 amplitude was significantly correlated with the adiponectin/leptin ratio. These findings indicate that healthy obese women still exhibit deviant neurophysiological performance when performing Go/Nogo and Stroop tasks, where the adiponectin/leptin ratio could be one of the influencing factors for the deficit in neural processes of motor response inhibition.
\end{abstract}

Keywords: obesity; inhibitory control; event-related potential; inflammatory cytokine; adiponectin/ leptin ratio

\section{Introduction}

Obesity has been associated not only with non-communicable diseases, but has also been found to be related to reduced brain volume (e.g., frontal cortex and anterior cingulate cortex) and impaired neurocognitive outcomes (e.g., frontal-lobe-based executive functions) [1]. Although it is known that obesity is caused by multidimensional factors [2], evidence indicates a relationship between obesity and neural circuits related to cognitive control functions. A recent systematic review paper reported that inhibitory control is significantly impaired in obese adults and children compared to normal-weight, 
healthy individuals since individuals with obesity feel that they have failed to resist food (overeating behavior) [3,4].

Inhibitory control, as a subcomponent of executive functions, refers to an individual's capacity to suppress a prepotent but ineffective behavior provoked by an external cue to stop an ongoing response and to resist distracting stimuli [5]. Such cognitive processing capabilities have been associated with many different aspects of life, being positively related to general success in health and the accumulation of wealth [6] and negatively related to addictions [7] and obesity [8]. The inhibitory control functions regulated and supported by multiple top-down neural connections [9] could be impaired in obese individuals. Indeed, obese individuals demonstrate characteristics of weak inhibitory control, which is considered to play a critical role in difficulties related to resisting external cues that suggest delicious food $[10,11]$. These behavioral characteristics may be associated with dopamine-modulated mesolimbic circuits and the dorsolateral regions of the prefrontal cortex [10]. In comparison with normal-weight controls, obese adults have also exhibited lower dopamine D2 receptor density in the striatum, which is associated with higher metabolic activity in the prefrontal regions involved in inhibitory control and could be a potential mechanism contributing to overeating [12].

Inhibitory control could be fractionated into two functional subcomponents: response inhibition/behavioral control (i.e., the process of countermanding a prepotent motor response) and interference control/attentional inhibition (i.e., the ability to resist interference from stimuli in the external environment) [13]. In the present study, two inhibitory tasks, Go/Nogo and Stroop, were adopted to be as homogeneous as possible in terms of visual-spatial presentation and motor requirements. The two cognitive tasks activate different task-relevant fronto-cingulo-striatal neural networks, i.e., predominantly right fronto-striatal regions during the $\mathrm{Go} / \mathrm{Nogo}$ task and left-hemispheric parieto-temporal and fronto-striatal regions during the Stroop task [14]. Therefore, the neurocognitive mechanism underlying non-selective motoric stopping on the Go/Nogo task is considered to be behaviorally and neurobiologically distinct from the one implicated in response selection on the Stroop task [15]. Indeed, previous studies have used these two cognitive tasks to assess motor response inhibition (e.g., Go/Nogo task) and cognitive interference inhibition (e.g., Stroop task) in 10-year-old overweight/obese children. The results indicated divergent behavioral and cognitive electrophysiological performance [e.g., higher reaction time (RT) variability and lower P3 amplitude in the Go/Nogo task and longer RTs in the Stroop task] between normal-weight and overweight/obese groups [16].

An EEG is ideal for capturing the rapid processes involved in inhibitory control. The N2 and P3 event-related potential (ERP) components are commonly studied in relation to inhibitory control [17-19]. $\mathrm{N} 2$, an early negative deflection occurring around 200-400 ms post-stimulus, is mainly associated with conflict monitoring processes $[20,21]$. The following P3 wave, a positive component occurring around 300-600 ms post-stimulus, is associated with inhibition processing or attentional engagement [22,23]. The two ERP components have been demonstrated to be effective in terms of differentiating cognitive electrophysiological performance in obese and normal-weight individuals [16,24-26].

From the perspective of molecular biomarkers, obesity is considered to be an immunodeficient, chronic inflammation state, which may contribute to an increased risk of premature death [27]. Leptin is a pro-inflammatory cytokine produced by white adipose tissue and can cross the blood-brain barrier and blood-cerebrospinal fluid barrier via its central receptors in the hypothalamus and choroid plexus to elicit a negative feedback adiposity signal that regulates energy homeostasis in the human body [28]. Leptins have been proposed to be an early indicator of cognitive impairment [29]. Higher levels of leptin, consistent with more adipose tissue, are also associated with worse cognitive function [30,31]. Contrarily, adiponectin secreted by adipocytes has anti-inflammatory effects. Obesity and visceral adiposity are inversely correlated to adiponectin concentrations [32], normalizing following weight loss [33]. Higher adiponectin levels have been shown to be associated with cognitive performance in women [34]. In addition, the adiponectin/leptin ratio is a functional biomarker of adipose tissue inflammation [35]. Higher BMI is well-known to be associated with elevations in the peripheral levels 
of C-reactive protein (CRP). Poorer neuropsychological performance (e.g., slower RTs and worse inhibitory attention control) and aberrant neural activity (e.g., smaller P3 amplitudes) have been found to be associated with higher levels of CRP in adults who are overweight or obese [31].

Although inhibitory control capacity has been explored in obese children [16,36], this type of cognitive deficit should be considered from a developmental psychopathology perspective due to the protracted development of the neural networks underlying inhibitory control [37]. More importantly, although obesity is associated with a decreased ability to modulate cognitive conflict during inhibitory control processing, the neurophysiological and biochemical mechanisms underlying the relationship between inhibitory control deficits and obesity remain poorly understood. Therefore, the current study investigated the cognitive electrophysiological performance correlates of inhibitory control with motor response inhibition using the Go/Nogo task and cognitive interference inhibition using the Stroop task in sedentary obese women. In addition, since the peripheral levels of inflammatory cytokines are associated with neurocognitive performance, the correlations between biochemical markers and behavior/ERP performance when sedentary obese women performed the two cognitive tasks were also explored in the present study.

\section{Materials and Methods}

\subsection{Ethical Approval}

The participants gave informed consent prior to the study, which was approved by the Research Ethics Committee at Hualien Tzu Chi Hospital (approval number: IRB 105-61-A). This study conforms to the standards set by clause 35 of the Declaration of Helsinki, except for registration in a database.

\subsection{Participants}

With regard to Asian populations, the Western Pacific Regional Office of the World Health Organization (WPRO), led by the International Association for the Study of Obesity and the International Obesity Task Force, proposed a BMI of $23.0-24.9 \mathrm{~kg} / \mathrm{m}^{2}$ for overweight and BMI $\geq 25.0 \mathrm{~kg} / \mathrm{m}^{2}$ for obesity based on the related morbidity data and mortality risks $[38,39]$. The obese participants in the present study were thus defined as individuals with $B M I \geq 25.0 \mathrm{~kg} / \mathrm{m}^{2}$. According to this criterion and after conducting an a priori power analysis, it was indicated that $\sim 24$ participants was the minimum required sample size for each group to obtain a power of $70 \%$ and moderate effect sizes [40]. Twenty-six obese adults (obese group) and 26 age-matched normal-weight (BMI $<23.0 \mathrm{~kg} / \mathrm{m}^{2}$ ) adults (control group) aged between 21 and 45 years old were recruited from the community in Hualien City with the use of an informative flyer.

All participants were non-smokers and right handed, as measured by a handedness inventory [41]. They reported being free of any metabolic or cardiovascular diseases, neurological or psychiatric disorders, a history of head injury, or medication intake that influenced CNS functioning. None of the participants showed any symptoms of depression, as measured by the Beck depression inventory II (BDI-II; all scored below 13) [42], or cognitive impairments, as measured by the Mini-Mental State Examination (MMSE; all scored above 24) [43]. All participants had normal or corrected-to-normal vision. Demographic and body composition [e.g., BMI, circumferences, and percentage fat as measured with dual-energy $\mathrm{X}$-ray absorptiometry (DXA)] data for the two groups are provided in Table 1.

\subsection{Experimental Procedure}

All participants were required to make two visits to the cognitive neurophysiology laboratory. During the first visit, the research assistant explained the experimental procedure. She then asked the participants to complete an informed consent form, as well as a medical history and demographic questionnaire, the MMSE, the BDI-II, and a handedness inventory. The height and weight of the participants were also measured to calculate their BMI. After finishing all of the questionnaires, two participants were scheduled in the morning of the same day to avoid circadian cycle bias. 
The participants arrived after fasting for $12 \mathrm{~h}$ and refraining from strenuous exercise and alcohol intake for $24 \mathrm{~h}$. Each participant was asked to arrive at the laboratory at about $07.50-08.30 \mathrm{~h}$ and underwent fasting blood sampling by a certified technician. After blood sampling, the participant was asked to sit in an adjustable chair in front of a computer screen in an acoustically shielded room with dimmed lights and was offered two pieces of toast to avoid hypoglycaemia. An electrocap and electro-oculographic (EOG) electrodes were attached to the scalp and face of each participant before the two cognitive task tests (Go/Nogo and Stroop tasks). The viewing distance was $\sim 75 \mathrm{~cm}$. After 10 practice trials to help the participants became familiar with the protocols of the two cognitive tasks, the participants then underwent a simultaneous formal cognitive task test with concomitant electrophysiological recording, during which they were asked to respond as quickly and accurately as possible. The two cognitive tasks were performed in a counterbalanced order. All participants performed the experiment at the same time of day to control for circadian influences.

Table 1. Demographic characteristics of the normal-weight (control) and obese women.

\begin{tabular}{|c|c|c|c|c|}
\hline Characteristics & $\begin{array}{l}\text { Control Group } \\
(n=26)\end{array}$ & $\begin{array}{c}\text { Obese Group } \\
(n=26)\end{array}$ & $t$ & $p$ Value \\
\hline Age (years) & $34.04 \pm 5.66$ & $34.44 \pm 5.77$ & -0.25 & 0.802 \\
\hline Height $(\mathrm{cm})$ & $161.06 \pm 6.31$ & $160.32 \pm 5.39$ & 0.45 & 0.653 \\
\hline Weight $(\mathrm{kg})$ * & $58.89 \pm 4.49$ & $75.80 \pm 11.43$ & -7.00 & $<0.001$ \\
\hline $\operatorname{BMI}\left(\mathrm{kg} / \mathrm{m}^{2}\right) *$ & $22.70 \pm 1.13$ & $29.41 \pm 3.52$ & -9.24 & $<0.001$ \\
\hline $\mathrm{SBP}(\mathrm{mmHg})$ * & $106.46 \pm 14.26$ & $115.60 \pm 12.46$ & -2.43 & 0.019 \\
\hline $\mathrm{DBP}(\mathrm{mmHg}) *$ & $68.00 \pm 9.43$ & $76.56 \pm 9.11$ & -3.30 & 0.002 \\
\hline Resting HR (bpm) & $72.23 \pm 7.64$ & $75.52 \pm 7.01$ & -1.60 & 0.116 \\
\hline Education (years) & $16.38 \pm 0.80$ & $16.00 \pm 1.41$ & 1.20 & 0.236 \\
\hline BDI-II & $11.08 \pm 9.91$ & $11.00 \pm 8.46$ & -0.74 & 0.460 \\
\hline MMSE & $29.77 \pm 0.43$ & $29.92 \pm 0.27$ & -1.54 & 0.135 \\
\hline PA energy expenditure (kcal/day) & $66.05 \pm 11.97$ & $64.42 \pm 10.96$ & 0.50 & 0.619 \\
\hline Dietary (kcal/day) & $2023.1 \pm 689.5$ & $1882.26 \pm 520.18$ & 0.80 & 0.429 \\
\hline \multicolumn{5}{|l|}{ Circumference } \\
\hline Waist $(\mathrm{cm})$ * & $75.55 \pm 3.96$ & $88.68 \pm 9.91$ & -6.26 & $<0.001$ \\
\hline Abdominal $(\mathrm{cm}) *$ & $84.09 \pm 6.12$ & $96.90 \pm 10.26$ & -5.44 & $<0.001$ \\
\hline $\operatorname{Hip}(\mathrm{cm}) *$ & $98.99 \pm 4.42$ & $110.64 \pm 7.02$ & -7.12 & $<0.001$ \\
\hline \multicolumn{5}{|l|}{ Percentage fat } \\
\hline Whole body $(\%)$ * & $34.25 \pm 3.89$ & $39.30 \pm 4.44$ & -4.33 & $<0.001$ \\
\hline Upper limbs (\%) * & $13.53 \pm 1.52$ & $14.99 \pm 1.66$ & -3.28 & 0.002 \\
\hline Trunk $(\%)$ & $44.44 \pm 4.71$ & $46.34 \pm 5.60$ & -1.32 & 0.194 \\
\hline Lower limb (\%) & $37.5 \pm 5.79$ & $35.46 \pm 6.14$ & 1.43 & 0.159 \\
\hline
\end{tabular}

BMI, body mass index; SBP: systolic blood pressure; DBP: diastolic blood pressure; HR: heart rate; bpm, beat per minute; BDI, Beck depression inventory; MMSE, mini-mental state examination; and PA, physical activity. Values are means \pm SD. $* p<0.05$.

During the second visit in the same week, a DXA measurement was scheduled to assess body composition at Tzu Chi hospital. Before that, the participants were double checked for height, weight, and blood pressure.

\subsection{Cognitive Task}

\subsubsection{Go/Nogo Task}

The Go/Nogo task [44] was presented using E-Prime 2.0 software (Psychological Software Tools, Pittsburgh, PA, USA). A "+" was shown prior to a square appearing on the screen. The participants were instructed to press the space bar as fast as possible whenever a green-colored square appeared on the screen (the Go condition) and to withhold pressing whenever a red-colored square was repeated a second time in succession (the Nogo condition). Each participant completed a practice block of 10 trials before the task began. The Go/Nogo task consisted of 200 trials ( 40 Nogo trials; 160 Go trials). RT was 
measured as the average time required to press the button after the stimuli. Accuracy rate (AR) was calculated as the percentage of correctly pressed keyboard buttons in response to both the indicative and distractor stimuli.

\subsubsection{Stroop Task}

A two-choice version of the Stroop task programmed using E-prime (Psychology Software Tools, Sharpsburg, PA, USA), which has been demonstrated to induce a clear Stroop interference in both young and older adults [45], was adopted in this study in order to minimize the influence of response selection on task performance. In addition, given the evidence that semantics significantly interfere with color naming [46] while color interferes very little with word reading, possibly because reading is a heavily trained and highly automated process in literate adults $[47,48]$, the color-naming condition was adopted in the present study to investigate the effect of obesity on neurocognitive functioning associated with Stroop interference. The stimuli were two color names in Chinese presented as "紅" (red) and "綠" (green). All stimuli were presented with $4.5 \times 4.5 \mathrm{~cm}$ letters in the center of a 21-in. cathode-ray tube display against a black background at an $80 \mathrm{~cm}$ distance. In the incongruent condition, the color of the word in the display was different from its word meaning, whereas in the congruent condition, the meaning of the word and its color matched. A single test block consisted of $50 \%$ incongruent and 50\% congruent trials, in a randomized order. Two blocks of 120 trials, for a total 240 trials, were presented to each participant, with a rest period of 2 min between blocks. Each stimulus appeared on the screen until the participant responded and the next stimulus appeared 1.5 to $2 \mathrm{~s}$ after the response. The participants were instructed to respond as quickly and accurately as possible with a button press from their index ("N" key) and middle ("M" key) fingers of their right hand on a computer in response to the color while ignoring the word meaning. The stimulus response pairs were counterbalanced across participants. All participants performed the Stroop task with simultaneous electrophysiological recording. After a practice block of 10 trials to ensure that the participants understood the task instruction, the formal test was administered to allow for collection of behavioral performance along with EEG data.

\subsection{Whole and Regional Body Composition}

Body composition was measured using dual energy X-ray absorptiometry (DXA; Discovery Wi, Hologic Inc., Bedford, MA, USA). The measurement was performed by a certified technician according to the standard operating procedure. The scanning instructions and procedures were standardized for all participants. The trunk region included the area from the bottom of the neckline to the top of the pelvis, excluding the arms. The mass output from the DXA scanner was expressed in grams. The accuracy of the densitometer was calibrated using the manufacturer's spine phantom with a known hydroxyapatite density each testing day.

\subsection{ERP Recording and Analysis}

The ERP was recorded using eego ${ }^{\mathrm{TM}}$ amplifier system (ANT Neuro, EE-211, revision Nr 1.2, Germany) from 64 scalp sites (10-10 system) with $\mathrm{Ag} / \mathrm{AgCl}$ electrodes (active electrodes) mounted in an elastic cap. All inter-electrode impedance was maintained below $5 \mathrm{~K} \Omega$. The raw EEG signal was acquired with an A/D rate of $500 \mathrm{~Hz} /$ channel, a band-pass filter of $0.1-50 \mathrm{~Hz}$, and a $60-\mathrm{Hz}$ notch filter. An offline electrooculographic correction was applied to the individual trials prior to averaging the ERP components. All trials with response error and artefacts (i.e., electrooculogram and electromyogram exceeding $\pm 100 \mu \mathrm{V}$ ) were discarded. The remaining effective ERP data were separately averaged offline and constructed from Go and Nogo conditions in the Go/Nogo task and from congruent and incongruent conditions in the Stroop task over a $1000 \mathrm{~ms}$ epoch beginning $200 \mathrm{~ms}$ prior to the onset of the target stimulus. The mean amplitudes and latencies of the N2 and P3 components were measured at the $\mathrm{Fz}, \mathrm{FCz}$, and $\mathrm{Cz}$ electrodes. The time windows for detection of the $\mathrm{N} 2$ and $\mathrm{P} 3$ components were 
150-350 ms and 350-600 ms, respectively. Latency was calculated as the time in milliseconds from stimulus onset to peak amplitude.

\subsection{Blood Sampling and Analysis}

Fasting blood samples were collected to determine the levels of CRP, leptin, and adiponectin. The participants were instructed to fast overnight and abstain from caffeine and alcohol for $12 \mathrm{~h}$ prior to blood sampling. A blood sample of approximately $10 \mathrm{~mL}$ was collected into an EDTA vacutainer tube via venipuncture in the antecubital fossa. The blood samples were centrifuged at $1000 \mathrm{~g}$ for $8 \mathrm{~min}$ at $4{ }^{\circ} \mathrm{C}$ within $30 \mathrm{~min}$ of collection. The plasma fraction was aliquoted in storage tubes and stored at $-80^{\circ} \mathrm{C}$ until analysis. The inflammatory biomarkers were assayed using commercially available kits according to the manufacturer's protocols. Plasma CRP (REF 378020, Beckman coulter Inc., CA, USA) was determined using a commercial enzyme-linked immunosorbent assay (ELISA) kit (UniCel ${ }^{\circledR}$ DxC 600/800 System(s) and SYNCHRON ${ }^{\circledR}$ Systems CAL 5 Plus, Beckman Coulter, Inc.). Plasma leptin (250 tubes, Cat. \# HL-81K, the Linco Research, Inc., Billerica, MO, USA) and adiponectin levels (125 tubes, Cat. \# HADP-61HK, the Linco Research, Inc., Billerica, MO, USA) were measured using a standardized RIA kit for humans (LINCO Research Inc., Chaska, MN, USA). All samples were assayed in duplicate and the mean of the two duplicate values was used in the statistical analyses.

\subsection{Data Processing and Statistical Analyses}

Repeated measure analyses of variance (RM-ANOVAs) were conducted using group (obese vs. control) as a between-subject factor. For the behavioral [RTs and accuracy rates (ARs)] data, the conditions were conducted as a within-subject factor (congruent vs. incongruent for the Stroop task; Go vs. Nogo for the Go/Nogo task except the RTs). For the ERP data, the electrode (Fz vs. FCz vs. $\mathrm{Cz}$ ) was also examined as a within-subject factor. Bonferroni post-hoc analyses were performed when there were significant differences. Partial Eta squared $\left(\eta_{p}{ }^{2}\right)$ was adopted to calculate effect sizes for significant main effects and interactions, with the following criteria used to determine the magnitude: 0.01-0.059 indicated a small effect size; $0.06-0.139$ indicated a medium effect size; and $>0.14$ indicated a large effect size. Correlations were used to analyze the relationships between the neurophysiological indices and the biomechanical biomarkers. Statistical analyses were conducted with SPSS software version 24.0 (SPSS Inc., Chicago, IL, USA). A $p$-value $\leq 0.05$ was considered statistically significant.

\section{Results}

\subsection{Demographic Data}

As shown in Table 1, the weight and circumference measures (e.g., BMI, waist girth, abdominal girth, and hip girth) differed significantly between the obese and control groups. Significant between-group differences in the body composition status were only found for whole body fat and upper limb fat percentages. The blood pressure (e.g., SBP and DBP) and bone health (e.g., BMD and T-score) fell in the normal range even though the data showed significant between-group differences. In addition, no significant differences were found in the values for the other demographic measures.

\subsection{Behavioral Performance}

The behavioral performance of the normal-weight and obese women is shown in Table 2. The numbers of usable trials are reported in the supplementary materials (see Table S1). Obese and control groups did not show a significant difference in the average number of trials for RTs (Go/Nogo task: Go trials, $p=0.751 \&$ Nogo trials, $p=0.790$; Stroop task: congruent trials, $p=0.473 \&$ incongruent trials, $p=0.502$ ). 
Table 2. Behavioral performance of the normal-weight (control) and obese women.

\begin{tabular}{ccc}
\hline Characteristics & $\begin{array}{c}\text { Control Group } \\
(\mathbf{n}=\mathbf{2 6})\end{array}$ & $\begin{array}{c}\text { Obese Group } \\
(\mathbf{n}=\mathbf{2 6})\end{array}$ \\
\hline Go/Nogo task & & \\
AR Go (\%) & $99.92 \pm 0.23$ & $99.90 \pm 0.20$ \\
AR Nogo $(\%)$ & $98.27 \pm 2.53$ & $98.40 \pm 2.69$ \\
RT Go (ms) & $479.44 \pm 75.42$ & $496.62 \pm 72.41$ \\
Stroop task & & \\
AR congruent $(\%)$ & $98.88 \pm 1.66$ & $99.12 \pm 0.93$ \\
AR incongruent $(\%)$ & $97.54 \pm 3.08$ & $97.04 \pm 2.70$ \\
RT congruent $(\mathrm{ms})$ & $526.39 \pm 64.45$ & $521.20 \pm 48.71$ \\
RT incongruent $(\mathrm{ms})$ & $569.94 \pm 97.87$ & $568.62 \pm 81.21$ \\
\hline \multicolumn{2}{c}{ AR, accuracy rate; RT, reaction time. Values are means $\pm \mathrm{SD}}$.
\end{tabular}

\subsubsection{Go/Nogo Task}

- $\quad$ Accuracy rate (AR)

The RM-ANOVA for the ARs showed a significant main effect of condition $\left[\mathrm{F}_{(1,50)}=19.07, p<0.001\right.$, $\left.\eta_{p}{ }^{2}=0.29\right]$, with the AR being significantly higher in the Go condition $(99.91 \pm 0.22 \%)$ than in the Nogo condition $(98.27 \pm 2.61 \%)$. No significant main effects of group $\left[\mathrm{F}_{(1,50)}=0.02, p=0.887\right]$ or significant interaction between group and condition $\left[\mathrm{F}_{(1,50)}=0.04, p=0.835\right]$ were found.

- $\quad$ Reaction time (RT)

A univariate variation analysis revealed no significant differences in the RT for group $\left[\mathrm{F}_{(1,50)}=0.69\right.$, $p=0.411]$ in the Go condition.

\subsubsection{Stroop Task}

- $\quad$ Accuracy Rate (AR)

The RM-ANOVA for the ARs showed a significant main effect of condition $\left[\mathrm{F}_{(1,50)}=27.76, p<0.001\right.$, $\left.\eta_{p}{ }^{2}=0.36\right]$, with the AR being significantly higher in the congruent condition $(97.13 \pm 13.80 \%)$ than in the incongruent condition $(95.42 \pm 13.79 \%)$. No significance main effects of group $\left[\mathrm{F}_{(1,50)}=1.02\right.$, $p=0.306]$ or significant interactions between group and condition $\left[\mathrm{F}_{(1,50)}=0.79, p=0.379\right]$ were found.

- $\quad$ Reaction time (RT)

The RM-ANOVA for the RTs showed a significant main effect of condition $\left[\mathrm{F}_{(1,50)}=60.83, p<0.001\right.$, $\left.\eta_{p}{ }^{2}=0.55\right]$, with the RT being significantly faster in the congruent condition ( $\left.523.50 \pm 59.90 \mathrm{~ms}\right)$ than in the incongruent condition $(568.35 \pm 90.09 \mathrm{~ms})$. No significant main effects of group $\left[\mathrm{F}_{(1,50)}=0.01\right.$, $p=0.925]$ or significant interactions between group and condition $\left[\mathrm{F}_{(1,50)}=0.19, p=0.663\right]$ were found. The value obtained when subtracting inhibitory control in the congruent RTs from the incongruent RTs showed a non-significant between-group difference [control vs. obese: $42.37 \mathrm{vs} .47 .42 \mathrm{~ms}, \mathrm{t}=-0.44$, $p=0.663]$.

\subsection{Electrophysiological Performance}

The numbers of usable trials are reported in the supplementary materials (see Table S1). Obese and control groups did not show a significant difference in the average number of trials for ERP analysis (Go/Nogo task: Go trials, $p=0.542$ and Nogo trials, $p=0.654$; Stroop task: congruent trials, $p=0.908$ and incongruent trials, $p=0.935$ ). 


\subsubsection{Go/Nogo Task}

Figures 1 and 2 display the grand-average ERP waveforms for the three midline electrodes during the Go/Nogo task and the Stroop task in the two groups.

\section{Go}

\section{Nogo}

- Obese group — Control group L Significance in amplitude
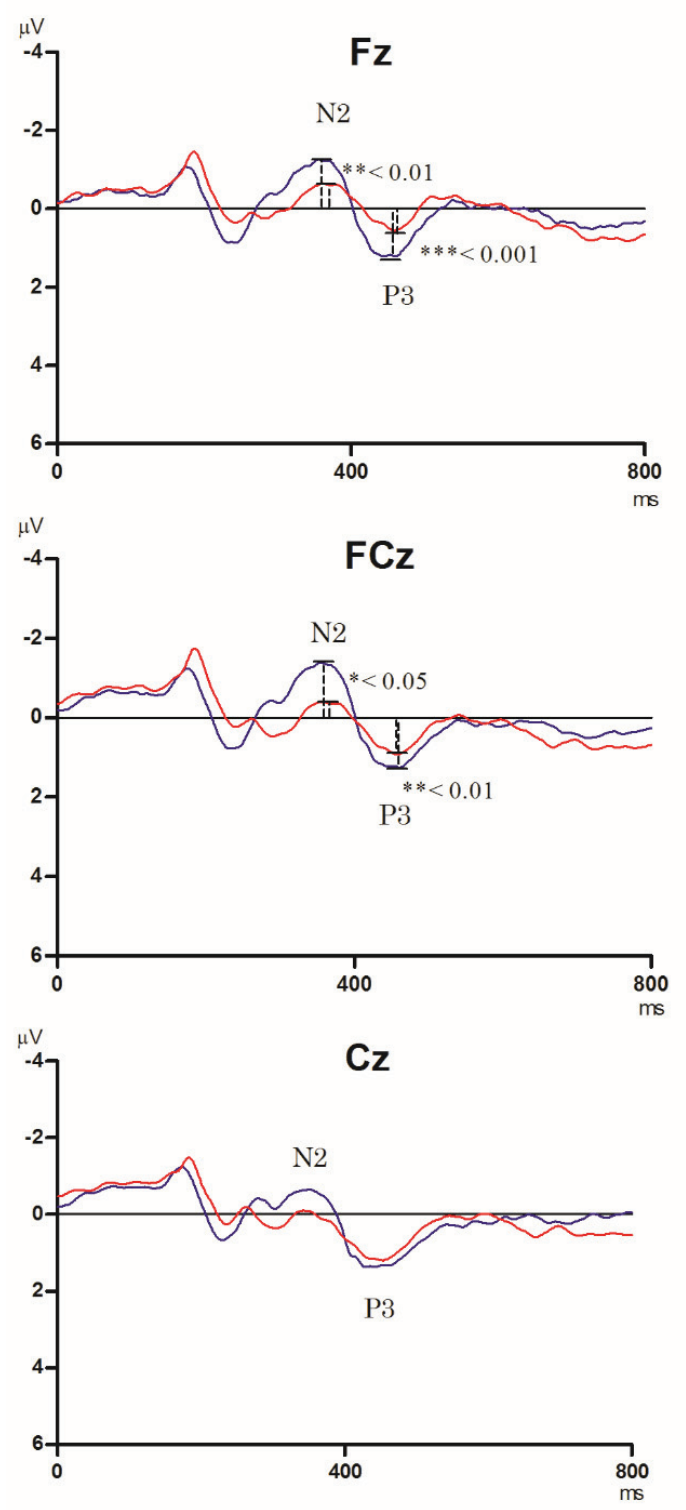
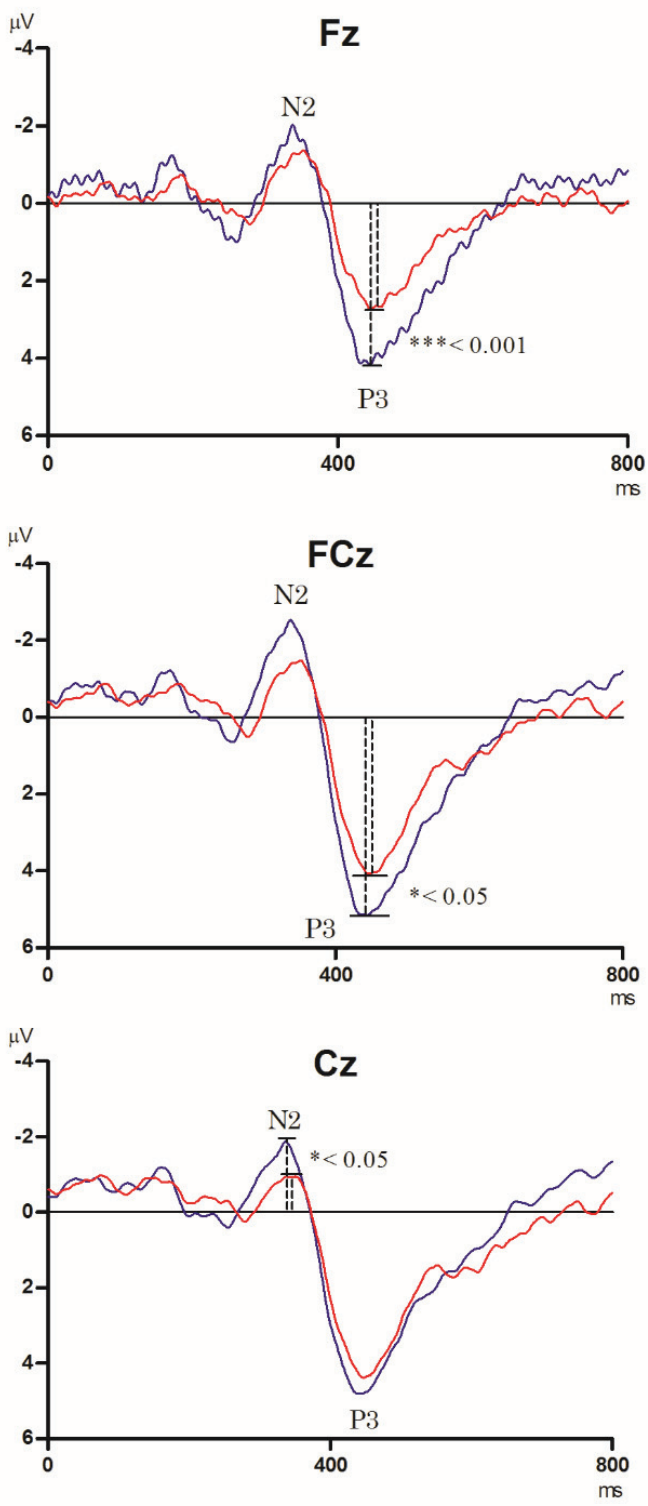

Figure 1. Grand averaged ERPs of N2 and P3 waveforms in the Go and Nogo conditions in three electrodes $(\mathrm{Fz}, \mathrm{FCz}$, and $\mathrm{Cz}$ ) for the normal-weight control group $(\mathrm{CG})$ and the obese group $(\mathrm{OG})$ in the Go/Nogo task.

\section{- $\quad \mathrm{N} 2$ component}

As shown in Figure 1, the RM-ANOVA for the N2 latency revealed a significant main effect of condition $\left[\mathrm{F}_{(1,50)}=4.65, p=0.036, \eta_{p}{ }^{2}=0.09\right]$, with the Go condition $(309.30 \pm 58.81 \mathrm{~ms})$ having a shorter N2 latency than the Nogo condition (327.08 $\pm 40.62 \mathrm{~ms})$. No significant main effects of group $\left[\mathrm{F}_{(1,50)}=1.18, p=0.284\right]$ and electrode $\left[\mathrm{F}_{(2,104)}=1.87, p=0.178\right]$ or significant interactions among group, 
condition, and electrode were observed [group $\times$ condition: $\mathrm{F}_{(1,50)}=0.14, p=0.713$; group $\times$ electrode: $\mathrm{F}_{(2,100)}=0.31, p=0.580 ;$ grou $\times$ condition $\times$ electrode: $\left.\mathrm{F}_{(2,98)}=0.35, p=0.558\right]$.

\section{Congruent}
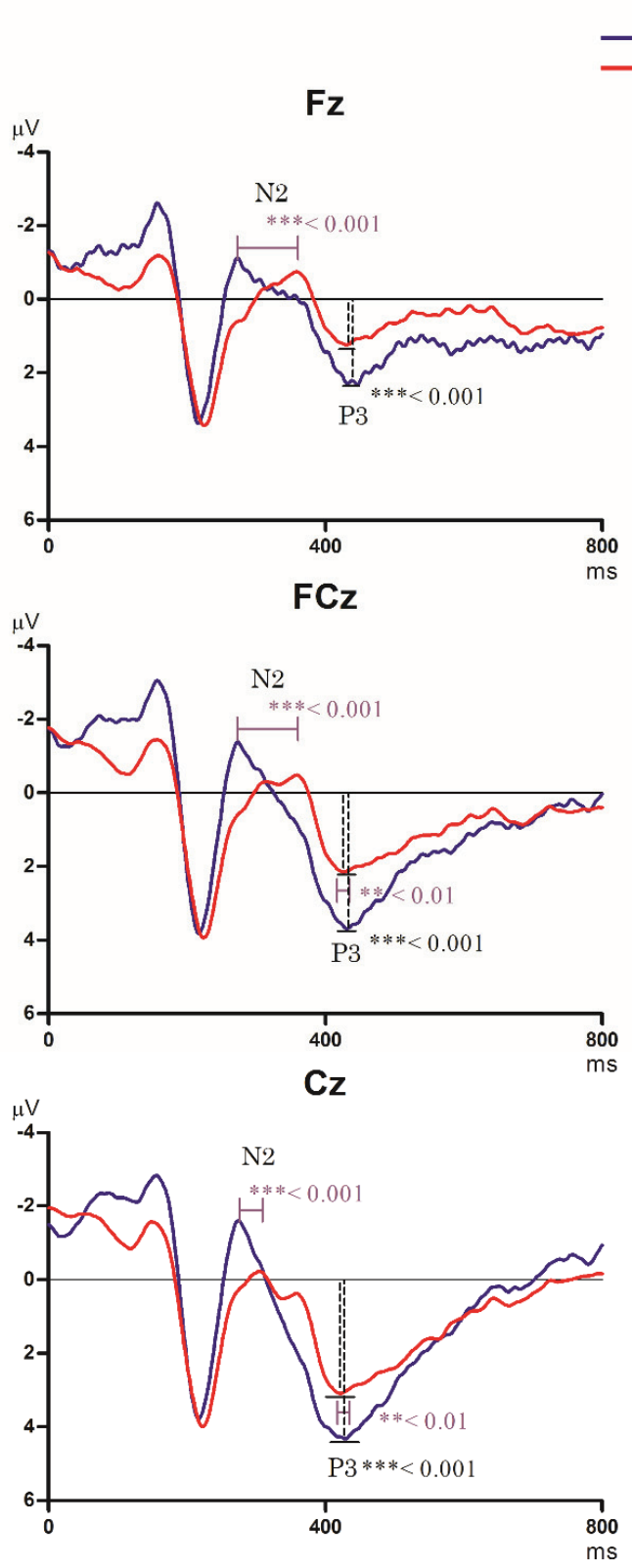

\section{Incongruent}
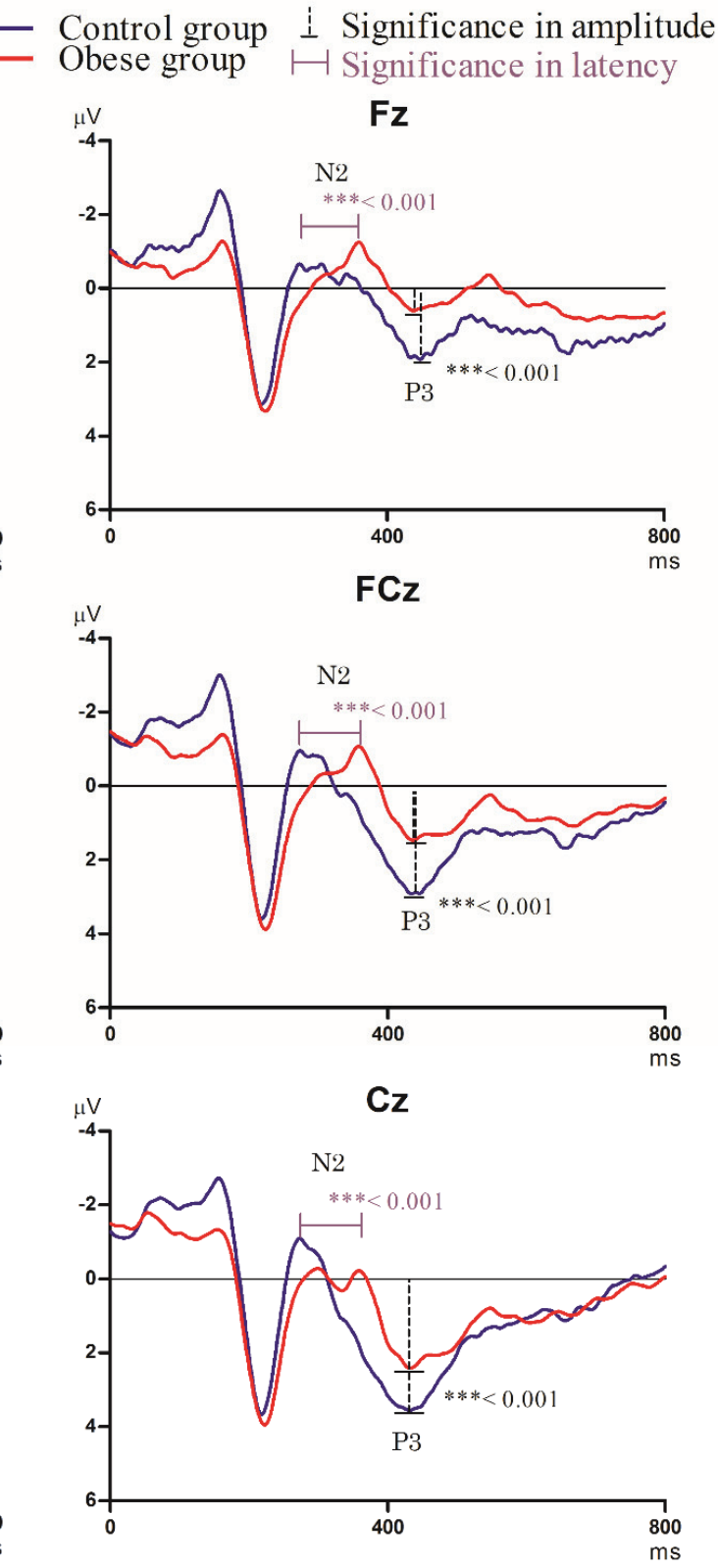

Figure 2. Grand averaged ERPs of N2 and P3 waveforms in the congruent and incongruent conditions in three electrodes $(\mathrm{Fz}, \mathrm{FCz}$, and $\mathrm{Cz}$ ) for the normal-weight control group (CG) and the obese group $(\mathrm{OG})$ in the Stroop task.

The RM-ANOVA for the N2 amplitude showed that there were significant main effects of group $\left[\mathrm{F}_{(1,50)}=5.52, p=0.023, \eta_{p}{ }^{2}=0.10\right]$ and condition $\left[\mathrm{F}_{(1,50)}=20.33, p<0.001, \eta_{p}{ }^{2}=0.29\right]$, with the control group $(-3.34 \pm 2.18 \mu \mathrm{V})$ exhibiting a smaller $\mathrm{N} 2$ amplitude than the obese group $(-2.12 \pm 1.43 \mu \mathrm{V}$, $p=0.023)$ and the Go condition $(-2.30 \pm 1.88 \mu \mathrm{V})$ showing a greater $\mathrm{N} 2$ amplitude than the Nogo condition $(-3.18 \pm 2.22 \mu \mathrm{V}, p<0.001)$ across the two groups. No significant main effects of electrode $\left[\mathrm{F}_{(2,104)}=0.01, p=0.914\right]$ or significant interactions among group, condition, and electrode were observed 
[group $\times$ condition: $\mathrm{F}_{(1,50)}=0.00, p=0.964 ;$ group $\times$ electrode: $\mathrm{F}_{(2,100)}=0.88, p=0.352 ;$ group $\times$ condition $\times$ electrode: $\left.\mathrm{F}_{(2,98)}=1.22, p=0.275\right]$.

- $\quad$ P3 component

The RM-ANOVA for the P3 latency revealed that there were no main effects of group $\left[\mathrm{F}_{(1,50)}=1.83\right.$, $p=0.182]$, electrode $\left[\mathrm{F}_{(2,104)}=1.33, p=0.270\right]$, and condition $\left[\mathrm{F}_{(1,50)}=0.97, p=0.329\right]$. No significant interactions among group, condition, and electrode were found [group $\times$ condition: $\mathrm{F}_{(1,50)}=1.49, p=0.228$; group $\times$ electrode: $\mathrm{F}_{(2,100)}=0.01, p=0.937$; group $\times$ condition $\times$ electrode: $\left.\mathrm{F}_{(2,98)}=0.41, p=0.526\right]$.

The RM-ANOVA for the P3 amplitude revealed significant main effects of group $\left[\mathrm{F}_{(1,50)}=19.19\right.$, $\left.p<0.001, \eta_{p}{ }^{2}=0.28\right]$, condition $\left[\mathrm{F}_{(1,50)}=667.41, p<0.001, \eta_{p}{ }^{2}=0.93\right]$, and electrode $\left[\mathrm{F}_{(2,104)}=56.75\right.$, $\left.p<0.001, \eta_{p}{ }^{2}=0.54\right]$, with the control group $(2.98 \pm 0.53 \mu \mathrm{V})$ exhibiting greater $\mathrm{P} 3$ amplitudes than the obese group $(2.34 \pm 0.51 \mu \mathrm{V})$, the Go condition $(1.11 \pm 0.30 \mu \mathrm{V})$ showing greater P3 amplitudes than the Nogo condition $(4.22 \pm 1.03 \mu \mathrm{V})$ across the two groups, and the $\mathrm{Cz}$ site $(2.93 \pm 0.69 \mu \mathrm{V})$ showing greater P3 amplitude than that of the Fz site $(2.19 \pm 0.77 \mu \mathrm{V})$. There were also significant main effects for group $\times$ condition $\left[\mathrm{F}_{(1,50)}=5.79, p=0.020, \eta_{p}{ }^{2}=0.11\right]$ and group $\times$ electrode interactions $\left[\mathrm{F}_{(2,100)}=13.37\right.$, $\left.p=0.001, \eta_{p}{ }^{2}=0.21\right]$, with the obese group showing smaller P3 amplitudes than the control group in the Go $(0.93 \pm 0.26 \mu \mathrm{V}$ vs. $1.28 \pm 0.22 \mu \mathrm{V}, p<0.001)$ and Nogo $(3.74 \pm 0.93 \mu \mathrm{V}$ vs. $4.67 \pm 0.92 \mu \mathrm{V}$, $p=0.001$ ) conditions, with the obese relative to the control group exhibiting smaller P3 amplitudes at the Fz $(1.67 \pm 0.65 \mu \mathrm{V}$ vs. $2.69 \pm 0.49 \mu \mathrm{V}, p<0.001)$ and FCz $(2.57 \pm 0.60 \mu \mathrm{V}$ vs. $3.16 \pm 0.68 \mu \mathrm{V}, p=0.001)$ sites. However, no significant interactions among group, condition, and electrode were observed [group $\times$ condition $\times$ electrode: $\mathrm{F}_{(2,98)}=1.86, p=0.179$ ].

Since blood pressure is a confounding factor with regard to cognitive electrophysiological performance of visuospatial attention in adults [49] and the obese group had significantly higher SBP and DBP compared to the normal-weight control group (see Table 1), the ERP components, N2 and P3 amplitudes, were used to account for blood pressure using an analysis of covariance (ANCOVA) procedure. The results of the RM-ANCOVA on the P3 amplitude across the two conditions still indicated a significant main effect of group $\left[\mathrm{F}_{(1,48)}=14.85, p<0.001, \eta_{p}{ }^{2}=0.24\right]$. However, the results of RM-ANCOVA on the N2 amplitude across the two conditions indicated a non-significant main effect of group $\left[\mathrm{F}_{(1,48)}=3.83, p=0.056\right]$.

\subsubsection{Stroop Task}

\section{- $\quad \mathrm{N} 2$ component}

As shown in Figure 2, the RM-ANOVA for the N2 latency showed a significant main effect of group $\left[\mathrm{F}_{(1,50)}=5.09, p=0.029, \eta_{p}{ }^{2}=0.098\right]$, with the obese group ( $\left.358.49 \pm 9.07 \mathrm{~ms}\right)$ exhibiting a longer $\mathrm{N} 2$ latency than the control group $(274.85 \pm 9.46 \mathrm{~ms})$. No significant main effects of condition $\left[\mathrm{F}_{(1,50)}=0.22\right.$, $p=0.644]$ and electrode $\left[\mathrm{F}_{(1,50)}=0.05, p=0.829\right]$ or significant interactions among group, condition, and electrode were observed [group $\times$ condition: $\mathrm{F}_{(1,50)}=0.25, p=0.622 ;$ group $\times$ electrode: $\mathrm{F}_{(2,100)}=2.97$, $p=0.092 ;$ group $\times$ condition $\times$ electrode: $\left.\mathrm{F}_{(2,98)}=1.36, p=0.249\right]$.

In terms of $\mathrm{N} 2$ amplitude, there were no significant main effects for group $\left[\mathrm{F}_{(1,50)}=0.67, p=0.417\right]$, electrode $\left[\mathrm{F}_{(2,104)}=0.01, p=0.914\right]$, and condition $\left[\mathrm{F}_{(1,50)}=0.13, p=0.720\right]$. No significant interactions among group, condition, and electrode were observed [group $\times$ condition: $\mathrm{F}_{(1,50)}=1.33, p=0.255$; group $\times$ electrode: $\mathrm{F}_{(2,100)}=0.01, p=0.944 ;$ grou $\times$ condition $\times$ electrode: $\left.\mathrm{F}_{(2,98)}=0.03, p=0.858\right]$.

\section{- $\quad$ P3 component}

The RM-ANOVA for the P3 latency showed that there was a significant main effect of group $\left[\mathrm{F}_{(1,50)}=6.14, p=0.017, \eta_{p}{ }^{2}=0.12\right]$, with the obese group $(405.26 \pm 60.84 \mathrm{~ms})$ exhibiting a longer P3 latency than the control group $(368.29 \pm 42.99 \mathrm{~ms})$. No significant main effects of electrode $\left[\mathrm{F}_{(2,104)}=0.76\right.$, $p=0.473]$ and condition $\left[\mathrm{F}_{(1,50)}=0.16, p=0.689\right]$ were observed. No significant interactions among group, condition, and electrode were observed [group $\times$ condition: $\mathrm{F}_{(1,50)}=0.35, p=0.555$; group $\times$ electrode: $\mathrm{F}_{(2,100)}=0.84, p=0.365 ;$ group $\times$ condition $\times$ electrode: $\left.\mathrm{F}_{(2,98)}=0.04, p=0.852\right]$. 
In terms of the P3 amplitude, there were significant main effects of group $\left[\mathrm{F}_{(1,50)}=1514.68, p<.001\right.$, $\left.\eta_{p}{ }^{2}=0.97\right]$, condition $\left[\mathrm{F}_{(1,50)}=317.02, p<0.001, \eta_{p}{ }^{2}=0.871\right]$, and electrode $\left[\mathrm{F}_{(2,104)}=1097.80, p<0.001\right.$, $\left.\eta_{p}{ }^{2}=0.96\right]$, with the control group $(3.11 \pm 0.18 \mu \mathrm{V})$ exhibiting a greater $\mathrm{P} 3$ amplitude than the obese group $(1.64 \pm 0.05 \mu \mathrm{V})$ and greater $\mathrm{P} 3$ amplitude in the congruent condition $(2.72 \pm 0.82 \mu \mathrm{V})$ than in the incongruent condition $(2.12 \pm 0.70 \mu \mathrm{V})$ across the two groups, with the P3 amplitude at the $\mathrm{Cz}(3.34 \pm 0.72 \mu \mathrm{V})>\mathrm{FCz}(2.40 \pm 0.94 \mu \mathrm{V})>\mathrm{Fz}(1.51 \pm 0.65 \mu \mathrm{V})$. There were significant interactions among group, condition, and electrode [group $\times$ condition: $\mathrm{F}_{(1,50)}=7.31, p=0.010, \eta_{p}{ }^{2}=0.14$; group $\times$ condition $\times$ electrode: $\mathrm{F}_{(2,98)}=6.73, p=0.013, \eta_{p}{ }^{2}=0.13$ ]. The post hoc analysis showed that the P3 amplitudes at all electrodes (Fz: $1.16 \pm 0.07 \mu \mathrm{V}$; FCz: $1.51 \pm 0.02 \mu \mathrm{V}$; Cz: $2.98 \pm 0.06 \mu \mathrm{V}$ ) in the congruent condition in the obese group were significantly smaller than in the control group (Fz: $2.33 \pm 0.17 \mu \mathrm{V} ; \mathrm{FCz}: 3.64 \pm 0.16 \mu \mathrm{V} ; \mathrm{Cz}: 4.39 \pm 0.83 \mu \mathrm{V})$. Identically, the P3 amplitudes at all electrodes (Fz: $0.51 \pm 0.01 \mu \mathrm{V} ; \mathrm{FCz}: 1.31 \pm 0.02 \mu \mathrm{V} ; \mathrm{Cz}: 2.33 \pm 0.21 \mu \mathrm{V}$ ) in the incongruent condition in the obese group were significantly smaller than in the control group (Fz: $1.89 \pm 0.10 \mu \mathrm{V}$; FCz: $2.91 \pm 0.20 \mu \mathrm{V}$; Cz: $3.49 \pm 0.16 \mu \mathrm{V})$.

Since blood pressure is a confounding factor with regard to cognitive electrophysiological performance of visuospatial attention in adults [49] and the obese group had significantly higher SBP and DBP compared to the normal-weight control group (see Table 1), the ERP components, N2 and P3 amplitudes, were used to account for blood pressure using an analysis of covariance (ANCOVA) procedure. The results of the RM-ANCOVA on the N2 and P3 amplitudes across the two conditions still indicated a significant main effect of group $\left[\mathrm{N} 2: \mathrm{F}_{(1,48)}=831.56, p<0.001, \eta_{p}{ }^{2}=0.95 ; \mathrm{P} 3: \mathrm{F}_{(1,48)}=7.44\right.$, $\left.p=0.010, \eta_{p}^{2}=0.14\right]$.

\subsection{Biochemical Indices}

As shown in Figure 3, the levels of the biochemical indices (i.e., CRP, leptin, adiponectin, and adiponectin/leptin ratio) exhibited substantial group differences ( $p s<0.05$ in all cases). The obese group exhibited higher levels in inflammatory biomarkers (CRP and leptin) as compared to the control group ( $p s<0.05$ ). In addition, the levels of adiponectin and the adiponectin/leptin ratios were significantly lower in the obese group than in the control group.
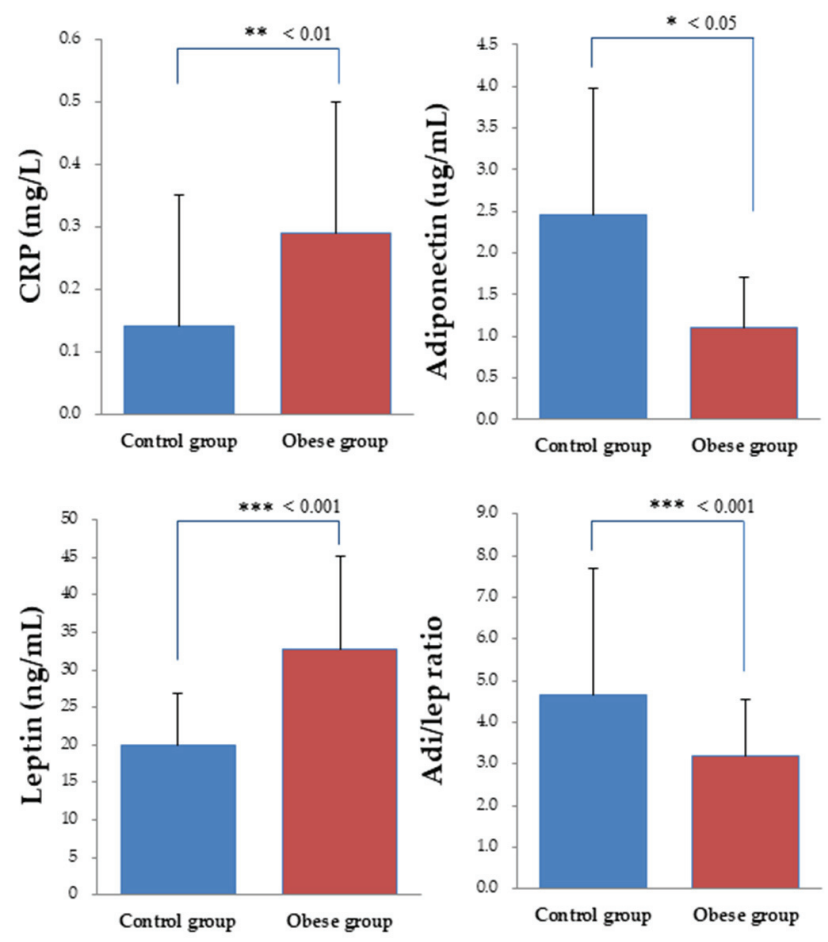

Figure 3. Biochemical values of the normal-weight control group and the obese group. 


\subsection{Correlations}

\subsubsection{Go/Nogo Task}

In the obese group, only the $\mathrm{P} 3$ amplitude across the three electrodes in the Nogo condition was significantly correlated with the adiponectin/leptin ratio $(r=0.40, p=0.049)$.

\subsubsection{Stroop Task}

Correlations between neurocognitive performance and the biochemical markers (i.e., CRP, leptin, adiponectin, and adiponectin/leptin ratio) in the obese group were not found.

\section{Discussion}

The aim of the present study was to explore the neurophysiological and molecular biochemical mechanism of executive control problems in obese women when performing two cognitive tasks involving different inhibitory control processes and to investigate the relationships between neurocognitive performance and the biochemical markers under consideration. The main findings indicated that although the obese and normal-weight women showed comparable ARs and RTs in the Stroop and Go/Nogo tasks, they exhibited longer N2 and P3 latencies and smaller P3 amplitudes across both conditions in the Stroop task and larger N2 amplitudes across both conditions and smaller P3 amplitudes in both the Go and Nogo conditions in the Go/Nogo task. Only the Nogo P3 amplitude in the obese group was positively correlated with the adiponectin/leptin ratio.

\subsection{Neurocognitive Performance}

In the present study, obese women showed comparable ARs and RTs to those of the normal-weight women in both the Stroop and Go/Nogo tasks, suggesting that obesity did not impact behavioral performance when they performed the two cognitive tasks with different inhibitory control processes. The present findings were somewhat inconsistent with earlier studies in which overweight/obese children relative to their normal-weight counterparts exhibited similar ARs, slower RTs in the Stroop task, and higher RT variability in the Go/Nogo task, suggesting impaired inhibitory control functions and a reduction in response efficiency in obese children [16]. In addition, Tsai et al. (2016) also found that obese children showed significantly weaker inhibitory control of attention when performing a visuospatial attention task [36]. The lack of age-related effects on behavioral performance in these inhibitory-control-related tasks in the present and previous studies may be related to core cognitive processes that are in place early in development [50]. Although children and adolescents appear fully mature in their ability to recognize when they have made an error, activity in the dorsal anterior cingulate cortex, which is associated with correct trial performance, in these age groups differed from that in adults [50,51]. The development of inhibitory control as indicated from the brain activity of the caudate body using Go/Nogo and Stroop tasks increases from childhood to adulthood [50,52]. Hence, the performance of children and adolescents receives less support from such feedback signaling, implicating immature error regulation and error feedback utilization as a source of performance decrements at younger ages [50]. This could be a possible explanation for the contrasting behavioral results between children and adults related to obesity. Since the emergence of adult-level cognition is known to rely on the development of error-regulatory functions, particularly in the context of being able to voluntarily inhibit responses to task-irrelevant stimuli, the present study extended previous knowledge by showing that obese women exhibited consistent ARs and RTs, suggesting that their cognitive control is more stable and less prone to external influences [53].

The Stroop task, which predominantly addresses the left-hemispheric fronto-striatal and parieto-temporal regions [14], assesses cognitive interference inhibition, while the Go/Nogo task, by activating task-relevant fronto-cingulo-striatal neural networks, evaluates motor response inhibition [14]. This study showed that obese women relative to normal-weight women exhibit longer Stroop N2 and P3 latencies in the Stroop task, but not in the Go/Nogo task. These results are 
compatible with previous findings of a significant discrepancy in P3 latency in the Stroop task in adolescents [24] and a non-significant discrepancy between N2 and P3 latencies in the Go/Nogo task between obese children/adolescents and control groups [16,54]. Therefore, both previous studies and the present study presumably reflect dysfunction within the anterior cingulate or prefrontal cortex (i.e., longer N2 and P3 latencies in the Stroop task) [55-57] in cases of obesity, while task-relevant fronto-cingulo-striatal neural networks seem to be somewhat intact (i.e., comparable N2 and P3 latencies between obese and control groups in the Go/Nogo task).

Obese women produced a greater Go/Nogo N2 amplitude than normal-weight women in the current study, which concurred with earlier studies on obese adolescents [54], supporting that individuals suffering from obesity show neural deficits in underlying systems modulating conflict monitoring processes $[20,25,54,58]$. However, the deviant N2 amplitude between the two groups only approached significant when controlling for the blood pressure as a co-variate, suggesting that blood pressure could be a potential factor related to inhibitory control deficits in individuals with obesity when performing the Go/Nogo task. Nevertheless, obese individuals have been demonstrated to show compromised inhibitory control processes that are involved in multiple top-down neural connections $[9,16]$. Therefore, the prefrontal cortex can be viewed as a predictor, a mediator, or a causal agent of obesity [59].

P3 amplitude can be regarded as an index of a motivation-related attentional engagement $[26,60]$. Although Nijs et al. (2010) and Bauer et al. (2010) reported no significant differences between obese and normal-weight individuals for P3 amplitudes in different Stroop tasks [24,26], most studies have found that obese individuals exhibit reduced P3 amplitudes in the Go/Nogo task $[16,25,61]$. In the present study, smaller P3 amplitudes were observed not only in the Go/Nogo task, but also in the Stroop task in the obese women as compared to the normal-weight women. These findings support the premise that obese individuals compromise a later stage of the inhibitory process when actual inhibition of the motor system in the premotor cortex takes place [62,63]. Since P3 amplitude also represents more conscious and controlled attentional processing of information, the deviant P3 neural activity occurring in obese individuals could reflect fewer attentional resources being allocated to inhibitory control processes and greater difficulty in processing stimuli, which results in a problem related to efficiently recruiting the cognitive resources necessary to modulate the risk of overeating behavior followed by weight gain [64].

\subsection{Molecular Biomarkers and Correlations with Neurocognitive Performance}

In the present study, as expected, obese women exhibited higher levels of CRP and leptin, lower levels of adiponectin, and lower adiponectin/leptin ratios as compared to the normal-weight women. Our results were consistent with previous findings [30,31]. Obesity alone, in the absence of overt disease, is frequently accompanied by subclinical systemic inflammation marked by increased circulating levels of proinflammatory indicators such as CRP and leptin $[65,66]$. These two inflammatory proteins play a key role not only in regulating food intake and energy expenditure and enhancing insulin sensitivity $[30,67]$, but also in influencing hypothalamic function $[30,68]$ and neuronal degradation [69] and decreasing neuronal excitability [70]. The associations between leptin/CRP levels and neurophysiological performance in the current study were not observed in the obese women. These findings differ from those of a previous study in which ERP P3 amplitude was negatively correlated with both the levels of leptin and CRP in obese individuals when performing a visuospatial attention task [31], but partly concur with studies in which there were significant associations between leptin levels and neuropsychological performance in individuals with mild cognitive impairment. Obesity is well recognized as a state of inflammation in which increased levels of inflammatory biomarkers may interfere with leptin receptors and inhibit the neuroprotective effect on the brain. Higher levels of leptin have not been found to confer any neuroprotective benefit for overweight or obese women [71]. Additionally, from the point of view of gender differences, previous studies 
reported that leptin levels are not correlated with cognitive performance in women [72,73], but are in men [74].

The Nogo P3 amplitude in the obese women in the present study was positively correlated with the adiponectin/leptin ratio. To date, no previous studies have explored the relationship between the adiponectin/leptin ratio and neurocognitive performance in obese individuals. There is a possible explanation to account for the pattern of the findings on this topic. Adiponectin acts as an insulin-sensitizing hormone in muscle and liver, and lower levels of adiponectin further contribute to peripheral insulin resistance in obesity $[75,76]$. The adiponectin/leptin ratio is a functional biomarker of adipose tissue inflammation [77] and a good indicator of a dysfunctional adipose tissue, which may be a useful estimator of obesity and metabolic syndrome [77]. This emerging biomarker correlates with insulin resistance better than adiponectin or leptin alone [77], while insulin resistance correlates with cognitive dysfunction [78-80]. Since individuals with type 2 diabetes suffer from severe cognitive deficits [79] and deficits in hippocampal function may appear due to peripheral insulin resistance and hyperlipidemia caused by a high-calorie diet, which declines hippocampal synaptic plasticity and impairs cognitive function [80], this is a plausible reason for the significant correlation between the adiponectin/leptin ratio and the neurophysiological performance observed in the present study.

\subsection{Limitations}

Although this is the first study to examine the neurocognitive inhibitory control ability performance and correlations with biochemical markers in obese women, where the confounding factors were rigorously controlled, there are still some potential limitations to the cross-sectional study design. First, an earlier study reported that there might be an effect of obesity on cognitive function that is only observable in men [81]. The association between adiposity-related indices (e.g., BMI and body fat $\%$ ) and low-grade systemic inflammation (e.g., CRP and leptin) is considerably stronger in women than in men [82-84]. Also, visceral fat cannot completely explain the levels of adiponectin in women as compared to men [85]. Therefore, gender plays a significant role in pathophysiological changes and clinical manifestations due to a crucial effect of sex hormones on neurohumoral adipose tissue activity [86]. Future studies could examine these gender differences to re-evaluate neurocognitive performance and biochemical findings related to obesity. Second, thus far, the consensus has not been reached concerning the relationships between BMI/adiposity and cerebral cortical thickness [87-89]. An avenue for future work is to examine the possibility of whether the ERP signal could be affected by the possible adipose tissue differences on the scalp between obese and healthy-weight individuals. Third, ERP N2 and P3 components are affiliated with cognitive processes controlled at the levels of the anterior cingulate cortex and hippocampal and parietal cortical region [90,91]. Previous studies demonstrated that physical lesions (e.g., brain cortex and tissue) could affect the ERP waveform [91,92]. Therefore, deviant neurophysiological performance in the obese individuals in the present study could be attributed to brain structure being affected by obesity, not worse cognitive processes. This conjecture is somewhat speculative, but provides a basis for future research.

\section{Conclusions}

Healthy obese women relative to normal-weight women showed comparable behavioral indices when they performed the Go/Nogo and Stroop tasks in the present study. However, they still exhibited deviant neurophysiological performance in underlying neural systems modulating motor response inhibition and cognitive interference inhibition and higher levels of inflammatory cytokines. Regular exercise has been demonstrated to be effective to improve higher levels of inflammatory cytokines and compromised neural activity in obese adults [93]. Determining how to control the adiponectin/leptin ratio through a healthy lifestyle (e.g., performing physical activity and exercise) to mitigate the deficit in neural processes of motor response inhibition could be an important issue in clinical practice.

Supplementary Materials: The following are available online at http://www.mdpi.com/1660-4601/17/8/2726/s1, Table S1: Correct trials and count trials for ERP analysis in Go/Nogo. 
Author Contributions: Conceptualization, H.-J.W. and C.-L.T.; methodology, H.-J.W.; software, H.-J.W.; validation, H.-J.W.; formal analysis, H.-J.W.; investigation, H.-J.W.; resources, H.-J.W.; data curation, H.-J.W..; writing-original draft preparation, H.-J.W.; writing-review and editing, H.-J.W. and C.-L.T; visualization, H.-J.W.; supervision H.-J.W.; project administration, H.-J.W.; funding acquisition, H.-J.W. All authors have read and agreed to the published version of the manuscript.

Funding: This research was funded by the Ministry of Science and Technology (MOST 106-2410-H-320-004 and MOST 107-2410-H-320-005) and the Buddhist Tzu Chi Medical Foundation (TCMMP105-03-01), Taiwan.

Acknowledgments: We wish to express our appreciation for the cooperation of all participants and the facility support provided by Tzu Chi University. We also wish to acknowledge graduate student Ke-Hsin Chen for assisting with data collection and the technicians, Lu-Fa Wang and the Department of medical imaging at Tzu Chi Hospital, for assisting with the DXA measurements.

Conflicts of Interest: The authors declare no conflict of interest.

\section{References}

1. Carnell, S.; Gibson, C.; Benson, L.; Ochner, C.N.; Geliebter, A. Neuroimaging and obesity: Current knowledge and future directions. Obes. Rev. 2012, 13, 43-56. [CrossRef] [PubMed]

2. Berthoud, H.R. Metabolic and hedonic drives in the neural control of appetite: Who is the boss? Curr. Opin. Neurobiol. 2011, 21, 888-896. [CrossRef]

3. He, Q.; Xiao, L.; Xue, G.; Wong, S.; Ames, S.L.; Schembre, S.M.; Bechara, A. Poor ability to resist tempting calorie rich food is linked to altered balance between neural systems involved in urge and self-control. Nutr. J. 2014, 13, 92. [CrossRef] [PubMed]

4. Yang, Y.; Shields, G.S.; Guo, C.; Liu, Y. Executive function performance in obesity and overweight individuals: A meta-analysis and review. Neurosci. Biobehav. Rev. 2018, 84, 225-244. [CrossRef]

5. Nigg, J.T. On inhibition/disinhibition in developmental psychopathology: Views from cognitive and personality psychology and a working inhibition taxonomy. Psychol. Bull. 2000, 126, 220-246. [CrossRef] [PubMed]

6. Moffitt, T.E.; Arseneault, L.; Belsky, D.; Dickson, N.; Hancox, R.J.; Harrington, H.; Houts, R.; Poulton, R.; Roberts, B.W.; Ross, S.; et al. A gradient of childhood self-control predicts health, wealth, and public safety. Proc. Natl. Acad. Sci. USA 2011, 108, 2693-2698. [CrossRef] [PubMed]

7. Smith, J.L.; Johnstone, S.J.; Barry, R.J. Movement-related potentials in the Go/NoGo task: The P3 reflects both cognitive and motor inhibition. Clin. Neurophysiol. 2008, 119, 704-714. [CrossRef] [PubMed]

8. Hofmann, W.; Friese, M.; Roefs, A. Three ways to resist temptation: The independent contributions of executive attention, inhibitory control, and affect regulation to the impulse control of eating behavior. J. Exp. Soc. Psychol. 2009, 45, 431-435. [CrossRef]

9. Hwang, K.; Velanova, K.; Luna, B. Strengthening of top-down frontal cognitive control networks underlying the development of inhibitory control: A functional magnetic resonance imaging effective connectivity study. J. Neurosci. 2010, 30, 15535-15545. [CrossRef]

10. Appelhans, B.M. Neurobehavioral inhibition of reward-driven feeding: Implications for dieting and obesity. Obesity (Silver Spring) 2009, 17, 640-647. [CrossRef]

11. Davis, C.; Levitan, R.D.; Smith, M.; Tweed, S.; Curtis, C. Associations among overeating, overweight, and attention deficit/hyperactivity disorder: A structural equation modelling approach. Eat. Behav. 2006, 7, 266-274. [CrossRef] [PubMed]

12. Volkow, N.D.; Wang, G.J.; Telang, F.; Fowler, J.S.; Thanos, P.K.; Logan, J.; Alexoff, D.; Ding, Y.S.; Wong, C.; Ma, Y.; et al. Low dopamine striatal D2 receptors are associated with prefrontal metabolism in obese subjects: Possible contributing factors. Neuroimage 2008, 42, 1537-1543. [CrossRef] [PubMed]

13. Garon, N.; Bryson, S.E.; Smith, I.M. Executive function in preschoolers: A review using an integrative framework. Psychol. Bull. 2008, 134, 31-60. [CrossRef] [PubMed]

14. Rubia, K.; Smith, A.B.; Woolley, J.; Nosarti, C.; Heyman, I.; Taylor, E.; Brammer, M. Progressive increase of frontostriatal brain activation from childhood to adulthood during event-related tasks of cognitive control. Hum. Brain Mapp. 2006, 27, 973-993. [CrossRef] [PubMed]

15. Chambers, C.D.; Bellgrove, M.A.; Gould, I.C.; English, T.; Garavan, H.; McNaught, E.; Kamke, M.; Mattingley, J.B. Dissociable mechanisms of cognitive control in prefrontal and premotor cortex. J. Neurophysiol. 2007, 98, 3638-3647. [CrossRef] 
16. Reyes, S.; Peirano, P.; Peigneux, P.; Lozoff, B.; Algarin, C. Inhibitory control in otherwise healthy overweight 10-year-old children. Int. J. Obes. (Lond.) 2015, 39, 1230-1235. [CrossRef]

17. Bokura, H.; Yamaguchi, S.; Kobayashi, S. Electrophysiological correlates for response inhibition in a Go/NoGo task. Clin. Neurophysiol. 2001, 112, 2224-2232. [CrossRef]

18. Falkenstein, M. Inhibition, conflict and the Nogo-N2. Clin. Neurophysiol. 2006, 117, 1638-1640. [CrossRef]

19. Jonkman, L.M. The development of preparation, conflict monitoring and inhibition from early childhood to young adulthood: A Go/Nogo ERP study. Brain Res. 2006, 1097, 181-193. [CrossRef]

20. Ridderinkhof, K.R.; Ullsperger, M.; Crone, E.A.; Nieuwenhuis, S. The role of the medial frontal cortex in cognitive control. Science 2004, 306, 443-447. [CrossRef]

21. Watson, T.D.; Garvey, K.T. Neurocognitive correlates of processing food-related stimuli in a Go/No-go paradigm. Appetite 2013, 71, 40-47. [CrossRef] [PubMed]

22. Bruin, K.J.; Wijers, A.A.; van Staveren, A.S. Response priming in a go/nogo task: Do we have to explain the go/nogo N2 effect in terms of response activation instead of inhibition? Clin. Neurophysiol. 2001, 112, 1660-1671. [CrossRef]

23. Jonkman, L.M.; Lansbergen, M.; Stauder, J.E. Developmental differences in behavioral and event-related brain responses associated with response preparation and inhibition in a go/nogo task. Psychophysiology 2003, 40, 752-761. [CrossRef] [PubMed]

24. Bauer, L.O.; Kaplan, R.F.; Hesselbrock, V.M. P300 and the stroop effect in overweight minority adolescents. Neuropsychobiology 2010, 61, 180-187. [CrossRef]

25. Kamijo, K.; Pontifex, M.B.; Khan, N.A.; Raine, L.B.; Scudder, M.R.; Drollette, E.S.; Evans, E.M.; Castelli, D.M.; Hillman, C.H. The association of childhood obesity to neuroelectric indices of inhibition. Psychophysiology 2012, 49, 1361-1371. [CrossRef]

26. Nijs, I.M.; Franken, I.H.; Muris, P. Food-related Stroop interference in obese and normal-weight individuals: Behavioral and electrophysiological indices. Eat. Behav. 2010, 11, 258-265. [CrossRef]

27. Dixit, V.D. Adipose-immune interactions during obesity and caloric restriction: Reciprocal mechanisms regulating immunity and health span. J. Leukoc. Biol. 2008, 84, 882-892. [CrossRef]

28. Rosenbaum, M.; Leibel, R.L. 20 years of leptin: Role of leptin in energy homeostasis in humans. J. Endocrinol. 2014, 223, T83-T96. [CrossRef]

29. Johnston, J.M.; Hu, W.T.; Fardo, D.W.; Greco, S.J.; Perry, G.; Montine, T.J.; Trojanowski, J.Q.; Shaw, L.M.; Ashford, J.W.; Tezapsidis, N. Low plasma leptin in cognitively impaired ADNI subjects: Gender differences and diagnostic and therapeutic potential. Curr. Alzheimer Res. 2014, 11, 165-174. [CrossRef]

30. Gustafson, D.R.; Mielke, M.M.; Keating, S.A.; Holman, S.; Minkoff, H.; Crystal, H.A. Leptin, adiponectin and cognition in middle-aged HIV-infected and uninfected women. The Brooklyn women's interagency HIV study. J. Gerontol. Geriatr. Res. 2015, 4, 240. [CrossRef]

31. Tsai, C.L.; Huang, T.H.; Tsai, M.C. Neurocognitive performances of visuospatial attention and the correlations with metabolic and inflammatory biomarkers in adults with obesity. Exp. Physiol. 2017, 102, 1683-1699. [CrossRef] [PubMed]

32. Turer, A.T.; Khera, A.; Ayers, C.R.; Turer, C.B.; Grundy, S.M.; Vega, G.L.; Scherer, P.E. Adipose tissue mass and location affect circulating adiponectin levels. Diabetologia 2011, 54, 2515-2524. [CrossRef] [PubMed]

33. Varady, K.A.; Tussing, L.; Bhutani, S.; Braunschweig, C.L. Degree of weight loss required to improve adipokine concentrations and decrease fat cell size in severely obese women. Metabolism 2009, 58, 1096-1101. [CrossRef] [PubMed]

34. Wennberg, A.M.; Gustafson, D.; Hagen, C.E.; Roberts, R.O.; Knopman, D.; Jack, C.; Petersen, R.C.; Mielke, M.M. Serum adiponectin levels, neuroimaging, and cognition in the mayo clinic study of aging. J. Alzheimers Dis. 2016, 53, 573-581. [CrossRef]

35. Fruhbeck, G.; Catalan, V.; Rodriguez, A.; Ramirez, B.; Becerril, S.; Salvador, J.; Colina, I.; Gomez-Ambrosi, J. Adiponectin-leptin ratio is a functional biomarker of adipose tissue inflammation. Nutrients 2019, 11, 454. [CrossRef]

36. Tsai, C.L.; Chen, F.C.; Pan, C.Y.; Tseng, Y.T. The neurocognitive performance of visuospatial attention in children with obesity. Front. Psychol. 2016, 7, 1033. [CrossRef]

37. Nigg, J.T. Annual research review: On the relations among self-regulation, self-control, executive functioning, effortful control, cognitive control, impulsivity, risk-taking, and inhibition for developmental psychopathology. J. Child Psychol. Psychiatry 2017, 58, 361-383. [CrossRef] 
38. Wen, C.P.; David Cheng, T.Y.; Tsai, S.P.; Chan, H.T.; Hsu, H.L.; Hsu, C.C.; Eriksen, M.P. Are Asians at greater mortality risks for being overweight than Caucasians? Redefining obesity for Asians. Public Health Nutr. 2009, 12, 497-506. [CrossRef]

39. World Health Organization. The Asia-Pacific Perspective: Redefining Obesity and Its Treatment; Health Communications Australia: Sydney, Australia, 2000.

40. Cohen, J.E. Statistical Power Analysis for the Behavioral Sciences; Lawrence Erlbaum Associates: Hillsdale, NJ, USA, 1988.

41. Chapman, L.J.; Chapman, J.P. The measurement of handedness. Brain Cogn. 1987, 6, 175-183. [CrossRef]

42. Beck, A.T.; Steer, R.A.; Brown, G.K. BDI-II: 2nd Edition Manual; The Psychological Corporation: San Antonio, TX, USA, 1996.

43. Folstein, M.F.; Folstein, S.E.; McHugh, P.R. "Mini-mental state". A practical method for grading the cognitive state of patients for the clinician. J. Psychiatr. Res. 1975, 12, 189-198. [CrossRef]

44. Littel, M.; van den Berg, I.; Luijten, M.; van Rooij, A.J.; Keemink, L.; Franken, I.H. Error processing and response inhibition in excessive computer game players: An event-related potential study. Addict. Biol. 2012, 17, 934-947. [CrossRef]

45. Brink, J.M.; McDowd, J.M. Aging and selective attention: An issue of complexity or multiple mechanisms? J. Gerontol. B Psychol. Sci. Soc. Sci. 1999, 54, P30-P33. [CrossRef] [PubMed]

46. Gajewski, P.D.; Falkenstein, M. Long-term habitual physical activity is associated with lower distractibility in a Stroop interference task in aging: Behavioral and ERP evidence. Brain Cogn. 2015, 98, 87-101. [CrossRef] [PubMed]

47. MacLeod, C.M. Half a century of research on the Stroop effect: An integrative review. Psychol. Bull. 1991, 109, 163-203. [CrossRef] [PubMed]

48. Stroop, J.R. Studies of interference in serial verbal reactions. J. Exp. Psychol. 1935, 18, 643-662. [CrossRef]

49. Qiu, C.; Winblad, B.; Fratiglioni, L. The age-dependent relation of blood pressure to cognitive function and dementia. Lancet Neurol. 2005, 4, 487-499. [CrossRef]

50. Velanova, K.; Wheeler, M.E.; Luna, B. Maturational changes in anterior cingulate and frontoparietal recruitment support the development of error processing and inhibitory control. Cereb. Cortex 2008, 18, 2505-2522. [CrossRef]

51. Polli, F.E.; Barton, J.J.; Cain, M.S.; Thakkar, K.N.; Rauch, S.L.; Manoach, D.S. Rostral and dorsal anterior cingulate cortex make dissociable contributions during antisaccade error commission. Proc. Natl. Acad. Sci. USA 2005, 102, 15700-15705. [CrossRef]

52. Durston, S.; Thomas, K.M.; Worden, M.S.; Yang, Y.; Casey, B.J. The effect of preceding context on inhibition: An event-related fMRI study. Neuroimage 2002, 16, 449-453. [CrossRef] [PubMed]

53. Padmanabhan, A.; Geier, C.F.; Ordaz, S.J.; Teslovich, T.; Luna, B. Developmental changes in brain function underlying the influence of reward processing on inhibitory control. Dev. Cogn. Neurosci. 2011, 1, 517-529. [CrossRef]

54. Chen, S.; Jia, Y.; Woltering, S. Neural differences of inhibitory control between adolescents with obesity and their peers. Int. J. Obes. (Lond.) 2018, 42, 1753-1761. [CrossRef] [PubMed]

55. Huttenlocher, P.R.; Dabholkar, A.S. Regional differences in synaptogenesis in human cerebral cortex. J. Comp. Neurol. 1997, 387, 167-178. [CrossRef]

56. Pardo, J.V.; Pardo, P.J.; Janer, K.W.; Raichle, M.E. The anterior cingulate cortex mediates processing selection in the Stroop attentional conflict paradigm. Proc. Natl. Acad. Sci. USA 1990, 87, 256-259. [CrossRef] [PubMed]

57. Pfefferbaum, A.; Mathalon, D.H.; Sullivan, E.V.; Rawles, J.M.; Zipursky, R.B.; Lim, K.O. A quantitative magnetic resonance imaging study of changes in brain morphology from infancy to late adulthood. Arch. Neurol. 1994, 51, 874-887. [CrossRef] [PubMed]

58. Bekker, E.M.; Kenemans, J.L.; Verbaten, M.N. Source analysis of the N2 in a cued Go/NoGo task. Brain Res. Cogn. Brain Res. 2005, 22, 221-231. [CrossRef] [PubMed]

59. Lowe, C.J.; Reichelt, A.C.; Hall, P.A. The prefrontal cortex and obesity: A health neuroscience perspective. Trends Cogn. Sci. 2019, 23, 349-361. [CrossRef] [PubMed]

60. Band, G.P.; van Boxtel, G.J. Inhibitory motor control in stop paradigms: Review and reinterpretation of neural mechanisms. Acta Psychol. (Amst.) 1999, 101, 179-211. [CrossRef] 
61. Tascilar, M.E.; Turkkahraman, D.; Oz, O.; Yucel, M.; Taskesen, M.; Eker, I.; Abaci, A.; Dundaroz, R.; Ulas, U.H. P300 auditory event-related potentials in children with obesity: Is childhood obesity related to impairment in cognitive functions? Pediatr. Diabetes 2011, 12, 589-595. [CrossRef]

62. Dimoska, A.; Johnstone, S.J.; Barry, R.J. The auditory-evoked N2 and P3 components in the stop-signal task: Indices of inhibition, response-conflict or error-detection? Brain Cogn. 2006, 62, 98-112. [CrossRef]

63. Kok, A.; Ramautar, J.R.; De Ruiter, M.B.; Band, G.P.; Ridderinkhof, K.R. ERP components associated with successful and unsuccessful stopping in a stop-signal task. Psychophysiology 2004, 41, 9-20. [CrossRef]

64. Berthoud, H.R.; Morrison, C. The brain, appetite, and obesity. Ann. Rev. Psychol. 2008, 59, 55-92. [CrossRef] [PubMed]

65. Gleeson, M.; Bishop, N.C.; Stensel, D.J.; Lindley, M.R.; Mastana, S.S.; Nimmo, M.A. The anti-inflammatory effects of exercise: Mechanisms and implications for the prevention and treatment of disease. Nat. Rev. Immunol. 2011, 11, 607-615. [CrossRef] [PubMed]

66. Ouchi, N.; Parker, J.L.; Lugus, J.J.; Walsh, K. Adipokines in inflammation and metabolic disease. Nat. Rev. Immunol. 2011, 11, 85-97. [CrossRef] [PubMed]

67. Bluher, S.; Mantzoros, C.S. Leptin in humans: Lessons from translational research. Am. J. Clin. Nutr. 2009, 89, 991s-997s. [CrossRef]

68. Harvey, J.; Shanley, L.J.; O’Malley, D.; Irving, A.J. Leptin: A potential cognitive enhancer? Biochem. Soc. Trans. 2005, 33 Pt 5, 1029-1032. [CrossRef]

69. Cholerton, B.; Baker, L.D.; Craft, S. Insulin resistance and pathological brain ageing. Diabet. Med. 2011, 28, 1463-1475. [CrossRef] [PubMed]

70. Erbayat-Altay, E.; Yamada, K.A.; Wong, M.; Thio, L.L. Increased severity of pentylenetetrazol induced seizures in leptin deficient ob/ob mice. Neurosci. Lett. 2008, 433, 82-86. [CrossRef]

71. Zeki Al Hazzouri, A.; Stone, K.L.; Haan, M.N.; Yaffe, K. Leptin, mild cognitive impairment, and dementia among elderly women. J. Gerontol. A Biol. Sci. Med. Sci. 2013, 68, 175-180. [CrossRef]

72. Gustafson, D.R.; Backman, K.; Lissner, L.; Carlsson, L.; Waern, M.; Ostling, S.; Guo, X.; Bengtsson, C.; Skoog, I. Leptin and dementia over 32 years-the prospective population study of women. Alzheimers Dement. 2012, 8 , 272-277. [CrossRef]

73. Oania, R.; McEvoy, L.K. Plasma leptin levels are not predictive of dementia in patients with mild cognitive impairment. Age Ageing 2015, 44, 53-58. [CrossRef]

74. Warren, M.W.; Hynan, L.S.; Weiner, M.F. Leptin and cognition. Dement. Geriatr. Cogn. Disord. 2012, 33, 410-415. [CrossRef] [PubMed]

75. Forny-Germano, L.; De Felice, F.G.; Vieira, M. The role of leptin and adiponectin in obesity-associated cognitive decline and Alzheimer's disease. Front. Neurosci. 2018, 12, 1027. [CrossRef] [PubMed]

76. Yamauchi, T.; Kamon, J.; Waki, H.; Terauchi, Y.; Kubota, N.; Hara, K.; Mori, Y.; Ide, T.; Murakami, K.; Tsuboyama-Kasaoka, N.; et al. The fat-derived hormone adiponectin reverses insulin resistance associated with both lipoatrophy and obesity. Nat. Med. 2001, 7, 941-946. [CrossRef] [PubMed]

77. Fruhbeck, G.; Catalan, V.; Rodriguez, A.; Gomez-Ambrosi, J. Adiponectin-leptin ratio: A promising index to estimate adipose tissue dysfunction. Relation with obesity-associated cardiometabolic risk. Adipocyte 2018, 7, 57-62. [CrossRef]

78. Biessels, G.J.; Reagan, L.P. Hippocampal insulin resistance and cognitive dysfunction. Nat. Rev. Neurosci. 2015, 16, 660-671. [CrossRef]

79. Greenwood, C.E.; Winocur, G. High-fat diets, insulin resistance and declining cognitive function. Neurobiol. Aging 2005, 26 (Suppl. S1), 42-45. [CrossRef]

80. Stranahan, A.M.; Norman, E.D.; Lee, K.; Cutler, R.G.; Telljohann, R.S.; Egan, J.M.; Mattson, M.P. Diet-induced insulin resistance impairs hippocampal synaptic plasticity and cognition in middle-aged rats. Hippocampus 2008, 18, 1085-1088. [CrossRef]

81. Elias, M.F.; Elias, P.K.; Sullivan, L.M.; Wolf, P.A.; D'Agostino, R.B. Lower cognitive function in the presence of obesity and hypertension: The Framingham heart study. Int. J. Obes. Relat. Metab. Disord. 2003, 27, 260-268. [CrossRef]

82. Hunma, S.; Ramuth, H.; Miles-Chan, J.L.; Schutz, Y.; Montani, J.P.; Joonas, N.; Dulloo, A.G. Do gender and ethnic differences in fasting leptin in Indians and Creoles of Mauritius persist beyond differences in adiposity? Int. J. Obes. (Lond.) 2018, 42, 280-283. [CrossRef] 
83. Thorand, B.; Baumert, J.; Döring, A.; Herder, C.; Kolb, H.; Rathmann, W.; Giani, G.; Koenig, W. Sex differences in the relation of body composition to markers of inflammation. Atherosclerosis 2006, 184, 216-224. [CrossRef]

84. Thorand, B.; Baumert, J.; Kolb, H.; Meisinger, C.; Chambless, L.; Koenig, W.; Herder, C. Sex differences in the prediction of type 2 diabetes by inflammatory markers: results from the MONICA/KORA Augsburg case-cohort study, 1984-2002. Diabetes Care 2007, 30, 854-860. [CrossRef] [PubMed]

85. Christen, T.; Trompet, S.; Noordam, R.; van Klinken, J.B.; van Dijk, K.W.; Lamb, H.J.; Cobbaert, C.M.; den Heijer, M.; Jazet, I.M.; Jukema, J.W.; et al. Sex differences in body fat distribution are related to sex differences in serum leptin and adiponectin. Peptides 2018, 107, 25-31. [CrossRef] [PubMed]

86. Selthofer-Relatic, K.; Radic, R.; Stupin, A.; Sisljagic, V.; Bosnjak, I.; Bulj, N.; Selthofer, R.; Delic Brkljacic, D. Leptin/adiponectin ratio in overweight patients-Gender differences. Diabetes Vasc. Dis. Res. 2018, 15, 260-262.

87. Medic, N.; Kochunov, P.; Ziauddeen, H.; Ersche, K.D.; Nathan, P.J.; Ronan, L.; Fletcher, P.C. BMI-related cortical morphometry changes are associated with altered white matter structure. Int. J. Obes. (Lond.) 2019, 43, 523-532. [CrossRef] [PubMed]

88. Medic, N.; Ziauddeen, H.; Ersche, K.D.; Farooqi, I.S.; Bullmore, E.T.; Nathan, P.J.; Ronan, L.; Fletcher, P.C. Increased body mass index is associated with specific regional alterations in brain structure. Int. J. Obes. (Lond.) 2016, 40, 1177-1182. [CrossRef] [PubMed]

89. Sharkey, R.J.; Karama, S.; Dagher, A. Overweight is not associated with cortical thickness alterations in children. Front. Neurosci. 2015, 9, 24. [CrossRef]

90. Lange, J.J.; Wijers, A.A.; Mulder, L.J.; Mulder, G. Color selection and location selection in ERPs: Differences, similarities and neural specificity. Biol. Psychol. 1998, 48, 153-182. [CrossRef]

91. Nakajima, Y.; Miyamoto, K.; Kikuchi, M. Estimation of neural generators of cognitive potential P300 by dipole tracing method. No To Shinkei 1994, 46, 1059-1065.

92. Knight, R.T. Neural mechanisms of event-related potentials: Evidence from human lesion studies. In Event-Related Brain Potentials: Basic Issues and Applications; Oxford University Press: New York, NY, USA, 1990; pp. 3-18.

93. Tsai, C.L.; Pan, C.Y.; Chen, F.C.; Huang, T.H.; Tsai, M.C.; Chuang, C.Y. Differences in neurocognitive performance and metabolic and inflammatory indices in male adults with obesity as a function of regular exercise. Exp. Physiol. 2019, 104, 1650-1660. [CrossRef] 